\title{
T6 Yaşlandırma Isıl işlemi Uygulanan Ekstrude AA 7075 Alüminyum Alaşımlarının Mekanik Davranışları
}

\author{
Mehmet Demir, Okan Tekin and *Adem Demir \\ Faculty of Technology, Department of Metallurgical and Materials Engineering Sakarya University of Applied \\ Science, Turkey
}

\section{Özet}

AA 7075 dövme alaşımları T6 yaşlandırma ısıl işlemi ile yüksek mukavemetli üretilebildikleri için, havacılık sektöründe çokça tercih edilen alüminyum alaşımlarıdır. Dövme alaşımlar ayrıca döküm alaşımlarına göre daha boşluksuz ve de sünek özelliklere sahip olduğundan havacılık sektöründe güvenle kullanılırlar. Bu çalışmada havacılık sektöründe tercih edilen, ekstrüzyonla şekillendirilmiş 7075 alaşımlarına yaşlandırma ısıl işlemi uygulanmış ve alaşımın mekanik özelliklerinde ciddi bir artış sağlanmıştır. Bunu sağlamak için, exrude AA 7075 alaşımlarına ve $125^{\circ} \mathrm{C}$ ve $138^{\circ} \mathrm{C}$ olmak üzere iki farklı yaşlandırma ısıl işlem sıcaklığında T6 yaşlandırma ısıl işlemi uygulanmıştır. Öncelikle numenlerin hepsi $470^{\circ} \mathrm{C}$ de 5 saat süreyle çözeltiye alınmış, oda sıcaklığındaki suda hızla soğutulmuş ve aşırı doymuş çözelti elde edilmiştir. Numunelerin bir kısmı oda sıcaklığında doğal yaşlandırılmış bir kısmı $125^{\circ} \mathrm{C}$ ve bir kısmı da $138^{\circ} \mathrm{C}$ 'de farklı sürelerde yapay yaşlandırılmıştır ve her iki işlem sonucu $220 \mathrm{HV}$ sertliğe ulaşılmıştır. En yüksek mukavemet $604 \mathrm{MPa} 125^{\circ} \mathrm{C}$ de 50 saatlik ve $603 \mathrm{MPa} 138^{\circ} \mathrm{C}$ ve 10 saatlik yaşlandırmada elde edilmiştir. Yaşlandırma ısıl işlemi sonucu, akma mukavemetindeki artışın çekme mukavemeti artışından çok daha fazla olduğu gözlenmiştir.

Anahtar Kailimler: AA 7075 alüminyum alaşımları, çökelme sertleşmesi

\section{Abstract \\ Mechanical Behavior of T6 Age-Hardened AA 7075 Extruded Aluminum Alloys}

AA 7075 wrought alloys are highly preferred aluminium alloys in the aviation industry, as they can be produced with high strength by T6 aging heat treatment. In addition, forged alloys are used safely in the aviation industry because they have more void-free and ductile properties than casting alloys. In this study, aging heat treatment was applied to 7075 alloys, which are preferred in the aviation industry and formed by extrusion, and a significant increase was achieved in the mechanical properties of the alloy. To achieve this, T6 aging heat treatment was applied to the exrude AA 7075 alloys at two different aging heat treatment temperatures, $125^{\circ} \mathrm{C}$ and $138^{\circ} \mathrm{C}$. Initially, all samples were taken into solution at $470^{\circ}$ $\mathrm{C}$ for 5 hours, quickly cooled in water at room temperature and supersaturated solution was obtained. Some of the samples were naturally aged at room temperature, some were artificially aged at $125^{\circ} \mathrm{C}$ and some at $138^{\circ} \mathrm{C}$, and $220 \mathrm{HV}$ hardness was reached as a result of each processes. The highest strength was obtained at $604 \mathrm{MPa} 125^{\circ} \mathrm{C}$ for 50 hours and $603 \mathrm{MPa}$ at $138^{\circ} \mathrm{C}$ and 10 hours of aging. As a result of aging heat treatment, it has been observed that the increase in yield strength is much more than the increase in tensile strength.

Key words: AA 7075, aluminium alloys, precipitation hardening

*Corresponding author: Faculty of Technology, Department of Metallurgical and Materials Engineering Sakarya University of Applied Science, 54187, Sakarya TURKEY. E-mail address: ademir@subu.edu.tr, Phone: +902646160271 


\section{Introduction}

Alüminyum ve alaşımları hafifliği, korozyon dayanımı ve 1sıl işlemler sonrası yüksek mekanik dayanıma ulaşması nedeniyle paketleme, otomotiv, inşaat, havacılık ve uzay endüstrilerinde yaygın olarak kullanılan malzemelerden biridir. $7075(\mathrm{Al}-\mathrm{Zn}-\mathrm{Mg}-\mathrm{Cu})$ alüminyum alaşımı haddelenmiş veya ekstrude yarı-mamül olarak sahip olduğu düşük yoğunluk, yüksek mukavemet, süneklik, tokluk ve yorulma dayanımı gibi üstün özellikleri nedeniyle savunma, otomotiv ve havacılık sanayinde yaygın olarak kullanılmaktadır. Döküm ve dövme alüminyum alaşımlarında, mekanik özellikleri de 1 sıl işlem yoluyla daha üst seviyelere çıkarılabilmektedir. Alüminyum alaşımlarına uygulanan 1sıl işlemler, genelde malzemenin dayanım ve sertliğini artırmak için uygulanan çökelme sertleştirmesi işlemlerini kapsamaktadır.

Son yıllarda, sürdürülebilirlik için artan talep, hafif metallere dayalı gelişmiş yapısal malzemelerin geliştirilmesinde oldukça ilgi uyandırmıştır. $\mathrm{Al}, \mathrm{Mg}$, vb. ticari olarak temin edilebilen $\mathrm{Al}$ alaşımları, ulaşım ve havacılık da dahil olmak üzere birçok endüstride yaygın olarak kullanılmaktadır. Al alaşımları arasında, esas olarak Al-Zn-Mg-Cu'dan oluşan yaşlandırma yoluyla sertleştirilebilir 7075 alaşımı, mükemmel mekanik özellikler sergileyen ve bu nedenle birçok uygulamaya sahip önemli bir üyesidir [1],[2]. T6 işleminin (yapay yaşlandırma) 7075 alaşımını güçlendirmede etkili olduğu kanıtlanmıştır, bu sırada Al matrisi içinde çeşitli nano ölçekli ince çökeltiler oluşur ve dislokasyon hareketlerine engel olarak işlev görür [3]. Son 50 yılda, önemli sayıda çalışma, T6 1sıl işlem sırasında 7075'in mikroyapısal dönüşümüne odaklanmış ve çökelti fazlarının yapıları iyi anlaşılmaya çalışılmıştır. [[4], [5], [6]].

Gerçek uygulamalarda, 7075 alaşımları servis sırasında veya özellikle hava aracı bileşenleri olarak kullanıldığında olduğu gibi bakım sırasında kaçınılmaz olarak aşırı 1sınma yaşayabilir [7]. Yüksek sıcaklığa maruz kalma, bunlarla sınırlı olmamak üzere, aşağıdakileri içeren faktörlere bağlanabilir: süpersonik ve uçuş hızı sırasında aerodinamik ısıtma; motor bileşenlerinin yakınında oluşan yüksek sıcaklıklar; güneşte bir pistte boşta duran uçak ve sıcak gaz sızıntısı. Isıya maruz kalma, Al alaşımlarının özel mikro yapısına ciddi zararlar verebilir ve mekanik özelliklerin bozulmasına yol açabilir [7], [8], [9], [10].

Bu çalışmada 7075 alaşımların yaşlandırma isıl işlemi yoluyla en uygun çökelme sertleşmesi şartları belirlenmiş ve çekme ve sertlik gibi mekanik testlere tabi tutulmuştur. Bu sayede havacılık sektöründe güvenle kullanılabileceği akma sınırı araştırılmıştır.

\section{Deneysel Çalıșmalar}

Şekil 1 a) da görülen 7075 exdrude Al parçalar ASAŞ alüminyum fabrikasından $50 \mathrm{~mm}$ çapında ve $200 \mathrm{~mm}$ boyunda temin edilmiş ve farklı sürelerde T6 yaşlandırma ısıl işleminden geçirilmiş, gerekli mikro yapı ve mekanik özellikleri bu numuneler üzerinde incelenmiştir. Mikro yapı incelmeleri için 1sıl işlem görmüş numuneler makro olarak dağlanmış ve stereo mikroskopta görüntülenmiş ayrıca elektrolitik dağlama yapılarak mikroskopta mikro yapıları incelenmiştir. 
ASAŞ firmasından temin edilen exdrude 1sıl işlem görmemiş $7075 \mathrm{Al}$ parçalara mukavemet artış1 için T6 yaşlandırma 1sıl işlemi uygulanmıştır. Bunun için $\mathrm{Al}$ parçalar $470^{\circ} \mathrm{C}$ de 5 saat süreyle çözeltiye alınarak tane sınırında biriken segrege alaşım elementleri ve MgZn2 intermetaliği parçalanarak tane içine alınmaya çalışılmıştır. Çözeltiye alınan alaşım oda sıcaklığında suda hızla soğutulmuş ve aşırı doymuş çözelti elde edilmiştir. Soğutulan numuneler $125^{\circ} \mathrm{C}$ ve $138^{\circ} \mathrm{C}$ de yapay yaşlanması için 5,10,15,20,25 ve 50 saat süre tutulmuş ve yavaş soğutulmuştur. Ham ve 1sıl işlem görmüş numuneler tornada DIN 50125 standardına göre işlenerek Şekil 1 b) de görüldüğü gibi çekme testi numuneleri elde edilmiştir. Arta kalan parçalar $25 \mathrm{~mm}$ çapında ve $20 \mathrm{~mm}$ yüksekliğinde tornalanmış, sertlik ve mikro yapı numuneleri elde edilmiştir. Sertlik ölçümleri Vickers Hardness test cihazında ölçülmüş, parlatılan numuneler elektrolitik dağlanmış ve mikro yapı görüntüleri farklı büyütmelerde alınmıştır.

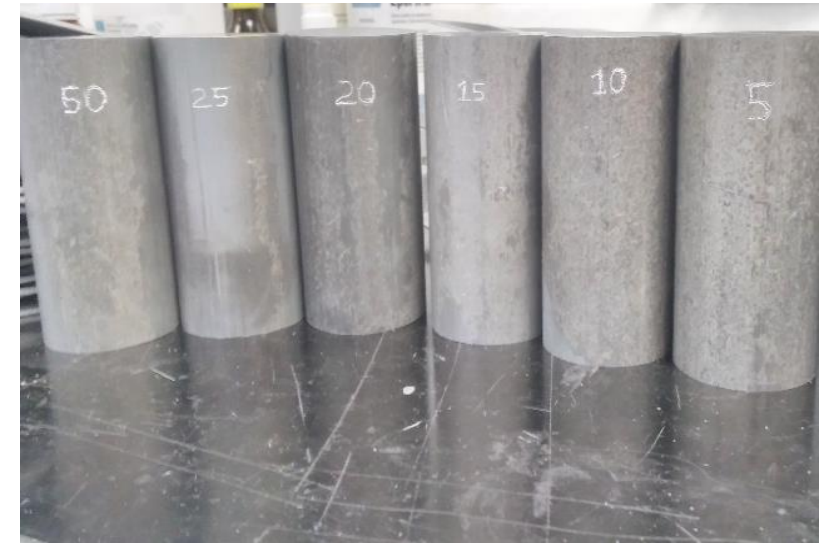

(a)

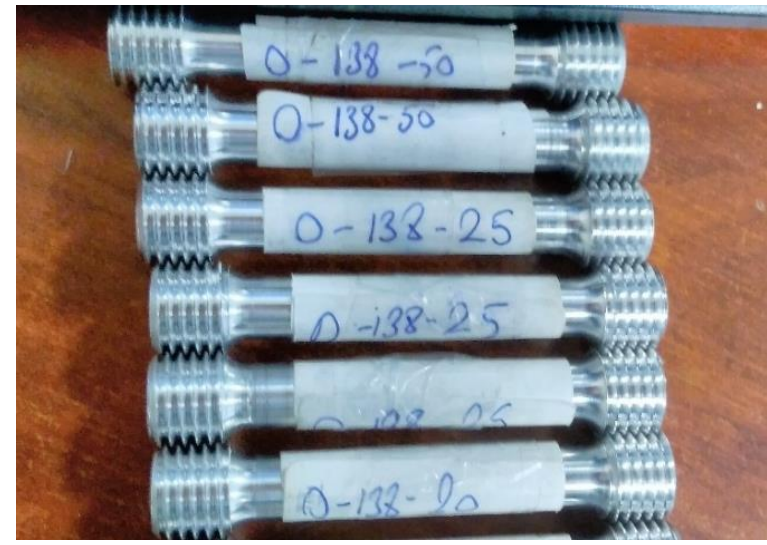

(b)

Şekil 1 a) Ekstrude AA 7075 alaşımı b) DIN 50125'e göre işlenmiş çekme numuneleri

\section{Sonuçlar ve İrdelenmesi}

AA 7075 dövme alüminyum alaşımının ana katkı maddesi olan çinko \% 5.6 civarında kullanılır ve alaşımlara çok yüksek çekme mukavemeti verir. Bu standartta, ana alaşım elementi olan çinko az miktarda magnezyumla kullanıldığında ısıl işlem tatbik edilebilen çok yüksek mukavemetli alaşımlar meydana gelmektedir. Çinkonun \% 8 den yüksek olması halinde, Al alaşımının dökülebilirliğini düşürmekte ve sıcak çatlamaya sebep olmaktadır. \% 5.6 Zn içeren $7075 \% 1.6 \mathrm{Cu}$ ve \% 2.5 Mg ilavesi dayanımı çok yüksek bir alaşım yapmaktadır [11].

Ana alaşım elementi çinko olmasına karşın, içinde mekanik özelliklerini etkileyen magnezyum ve bakır gibi ikincil alaşım elementi bulunmaktadır. Diğer alaşım elementleri eser miktarda miktardadır ve alaşımın mekanik ve fiziksel özelliklerine veya ısıl işlem davranışlarına fazlaca bir etkisi bulunmamaktadır. Ekstrüzyon öncesi billet dökümü sırasında $\mathrm{Zn}, \mathrm{Mg}$ ve $\mathrm{Cu}$ segrege olmakta tane sınırları alaşım elementlerince zenginleşmektedir. Tane içi ve tane sınırı arasında oluşan bu segregasyon, döküm sonrası homojenleştirme tavlamasıyla azaltılmaya çalışılır [12]. Homojenleştirilmiş dökümler ekstrüzyon sıcaklığına tekrar çıkarılır ve ekstrüzyon kalıbında 1/3 
oranında çap azaltılarak $50 \mathrm{~mm}$ çapında ekstrüzyon ile şekillendirilir. Ekstrüzyonla şekillendirilmiş AA $7075 \mathrm{Al}$ alaşımı parçaları firmadan temin edilerek bu çalışmaya başlanmıştır.

5-50 saat arasında farklı sürelerde yaşlandırma ısıl işlemi uygulanmış $7075 \mathrm{Al}$ numuneler parlatıldı ve optik mikroskop ile görüntülendi. Şekil 2 a'da bu alaşımının 5 saat çözeltiye alınmış ve Şekil 2 b'de 25 saat süreyle yaşlandırılmış numunelerinin stero mikroskop ile elde edilmiş makro yapı gözükmektedir. Makro yapı içerisine başta taneler arası, çatlaklar, boşluklar, metal dışı gayrı safsızlıklar (inklüzyonlar) ve bunun gibi makro hatalar girer. Hasar veya kusurların incelenmesinde yaygın olarak kullanılır. Mikro yapı incelemesine göre incelenecek alan çok daha geniştir. Detaylı olmasa da malzemelerin belli başlı yapısal özelliklerinin belirlenmesinde makro dağlama ile inceleme etkili bir yöntemdir. $125^{\circ} \mathrm{C}$ Yaşlandırma yapılan 5 ve 50 saatler arasındaki numunelerin makro yapıları aşağıda verilmiştir. Şekilde görüldüğü gibi herhangi bir gözenek hatası görülmemektedir. Ancak dendritik taneler arası bileşim farkı özellikle 5 saat yaşlandırılan numunede belirgin bir şekilde görülmektedir. Yaşlandırma süresinin artması yapının dendrit merkezlerindeki alaşım elementinin tane sınırına doğru difuze olmasına ve tane sınırlarına yakın bölgelerde çökelmesine yol açtığı anlaşılmaktadır.

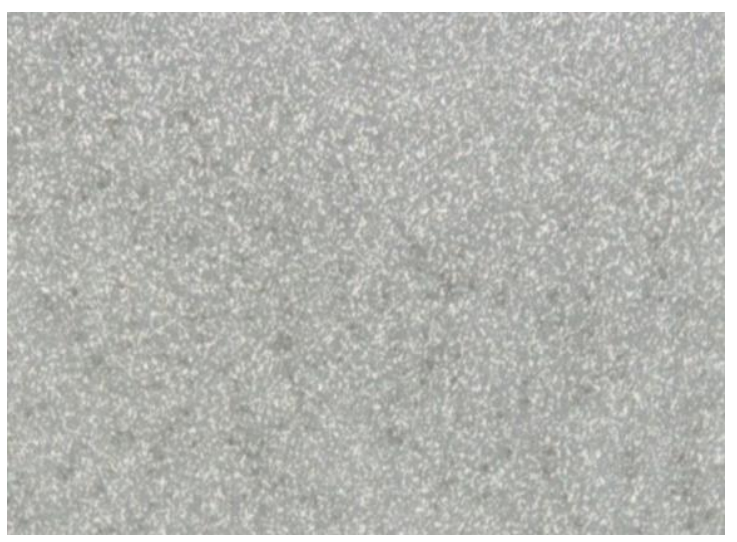

(a)

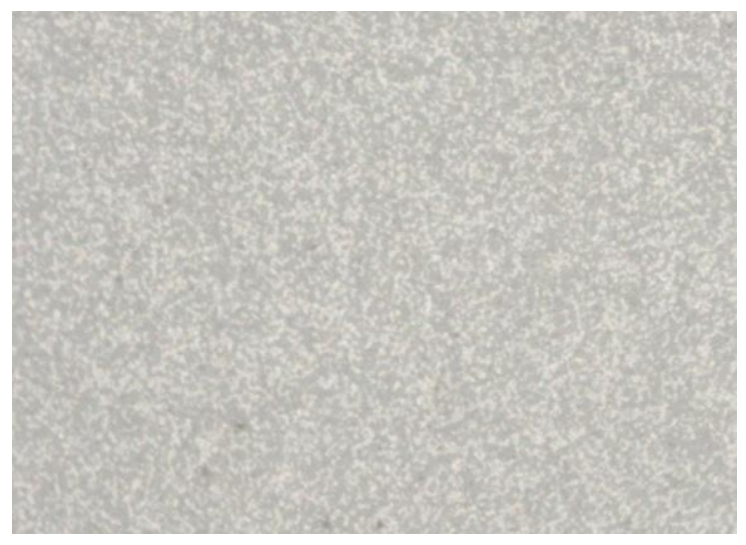

(b)

Şekil 2 a) $125^{\circ} \mathrm{C}-5$ saat yaşlandırma b) 25 Saat yaşlandırma

Farklı sürelerde çözeltiye alınmış ve farklı sürelerde yaşlandırılmış ekstruze numunelerin mikro yapı incelmeleri yapılmıştır. Mikro yapı kavramı içerisine tane sınırları, tane büyüklüğü, tane morfolojisi, tane içi unsurlar, ikincil fazlar segregasyonlar, mikro boşluklar ve mikro çatlaklar girmektedir. Metalografik tetkiklerde, mikroskobik incelemeler makroskobik incelemelerden daha ön planda olduğu için, ayıraç ve yöntemler bakımından mikro dağlama makro dağlamaya göre daha zengindir.

Bir elektroliz banyosu içerisinde anot olarak parlatılmış numunenin kullanılması suretiyle, metal veya alaşımdaki faz ve yapı bileşenlerinin ortaya çıkarılması işlemine elektrolitik dağlama denir. En etkili elektrolitik dağlama elektrolitik parlatma çözeltisindeki akım yoğunluğunun on misli veya daha fazla arttırılması ile elde edilir. 
Şekil 3 a ve b'de görülen mikro yapı görüntüleri elektrolitik dağlanarak polarize görüntülerdir. Parçalar döküm sonrası ekstrüzyonla şekillendirildiği için tane yapısı oldukça incedir. Yine de tane içi ile tane sınırı arasında bileşim farklılığı olduğu polarize 1şı farklılıklarından anlaşılmaktadır. 10 saat ve 25 saat yaşlandırma sonunda $\mathrm{MgZn}_{2}$ çökelmesi oranı artmaktadır bu da polarize renk dağılımını etkilediği anlaşılmaktadır.

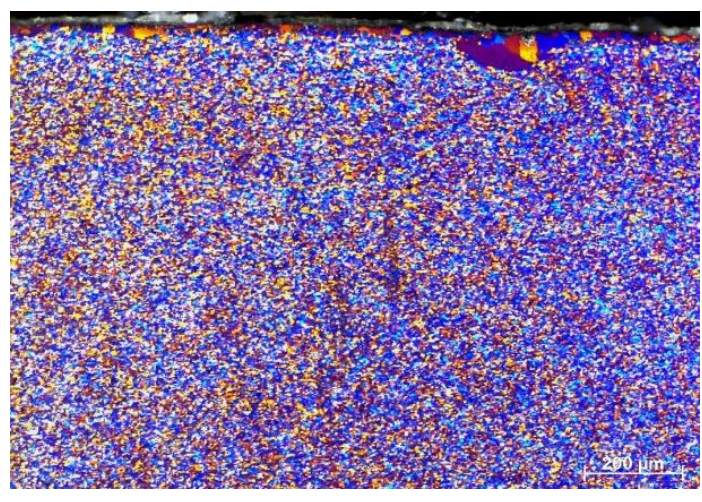

(a)

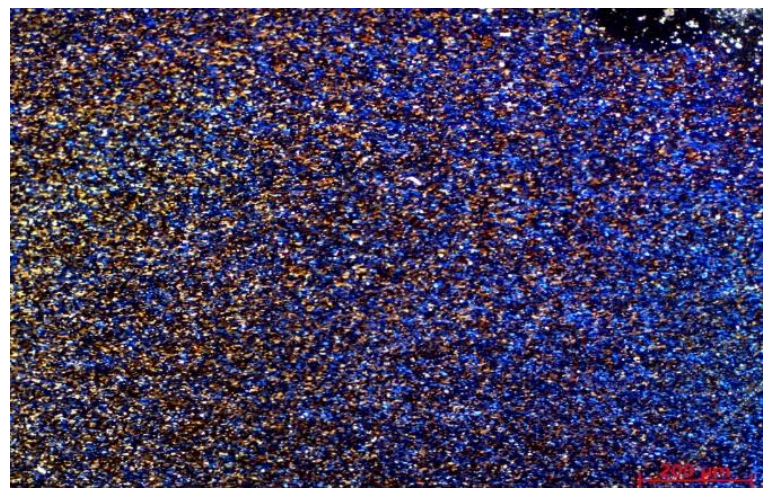

(b)

Şekil $3125^{\circ} \mathrm{C}^{\prime}$ de a) $10 \mathrm{~h}$ ve b) $25 \mathrm{~h}$ yaşlandırılmış polarize görüntüler

T6 yaşlandırma 1sıl işlemine tabi tutulan numunelerin Vickers sertlik değerleri ölçülmüş ve Şekil 4' de sertlik artışı grafik olarak verilmiştir. Isıl işlem görmemiş ekstrude numune 87.7 HV ölçülmüş ve 5 saatlik yaşlandırma süresi ile bu değer 149 HVdeğerine ulaşmıştır. Bundan sonra eğrinin artış1 yavaşlamış ve 20 saatlik yaşlandırma süresi ile $180.1 \mathrm{HV}$ değerine ulaşılabilmiştir. Isıl işlem süresinin 20 saatten 25 saate çıkarılmasıyla sertlikte hızlı bir artış gözlenmiş ve $220 \mathrm{HV}$ değerine ulaşılmıştır. Isıl işlem süresinin 25 saatten 50 saate çıkarılması ise çok fazla değiştirmemiş ve maksimim $225 \mathrm{HV}$ elde edilmiştir. Buradan kritik yaşlandırma süresinin $125^{\circ} \mathrm{C}$ de 25 saat olduğu anlaşılmaktadır. 25 saatlik bir yaşlandırma süresi ile literatürde belirtilen $200 \mathrm{HV}$ standart AA 7075 alaşımının sertlik değerinin üzerine ulaşılmıştır.

Yaşlandırma ısıl işlemi ile farklı sürelerde sertleştirilen numuneler çekme çubuğu olarak işlenmiş ve çekme testine tabi tutulmuştur. Elde edilen çekme testi sonuçları Tablo 1 ve Şekil 5 de verilmiştir. Tablo 1 de numerik sonuçlar, Şekil 5 de ise çekme testlerinin birleştirilmiş çekme grafikleri verilmiştir. İşlem görmemiş alaşımlar, oda sıcaklığında yaşlandırılmış alaşımlar ve $125^{\circ} \mathrm{C}$ 'de farklı sürelerde yapay yaşlandırılmış alaşımlar olmak üzere üç farklı türde numune test edilmiştir. Tablo 1 de görüldüğü gibi işlem görmemiş numenlerin en yüksek akma mukavemeti 222,08 MPa ve çekme mukavemeti 355,38 MPa gerçekleşmiştir. Oda sıcaklığında yaşlandırılan alaşımlar ise en yüksek akma mukavemeti 450,62 MPa ve çekme mukavemeti 602,64 MPa gerçekleşmiştir. Oda sıcaklığında oldukça yüksek mukavemet elde edilmiş, ancak akma mukavemeti $125^{\circ} \mathrm{C}$ yapay yaşlandırılmış numunelere göre düşük kalmıştır ve iki değer arsında 152 $\mathrm{MPa}$ fark ortaya çıkmıştır. Aslında oda sıcaklığında yaşlandırma ile hedef çekme değerine ulaşılmış ancak akma mukavemetine ulaşılamamıştır. $125^{\circ} \mathrm{C}$ de yaşlandırma süresi 5 saatten 50 saate kademeli artırılmasıyla çekme mukavemeti çok değişmemiş 50 saatlik 1sıl işlem sonucunda 604,70 MPa ile maksimuma ulaşmış ve akma mukavemeti ise her kademede ortalama artarak 555,06 $\mathrm{MPa}$ seviyesine ulaşmıştır. Dolayısıyla AA 7075 alaşımının oda sıcaklığında 
yaşlandırılması yerine, $125{ }^{\circ} \mathrm{C}$ yaşlandırılması akma mukavemetini ortalama $447 \mathrm{MPa}$ 'dan 555 MPa'a çıkarmıştır. Dolayısıyla sıcaklık altında gerçekleşen çökelme sertleşmesinin oda sıcaklığındaki doğal yaşlanmaya göre akma mukavemetini oldukça yükselttiği söylenebilir.

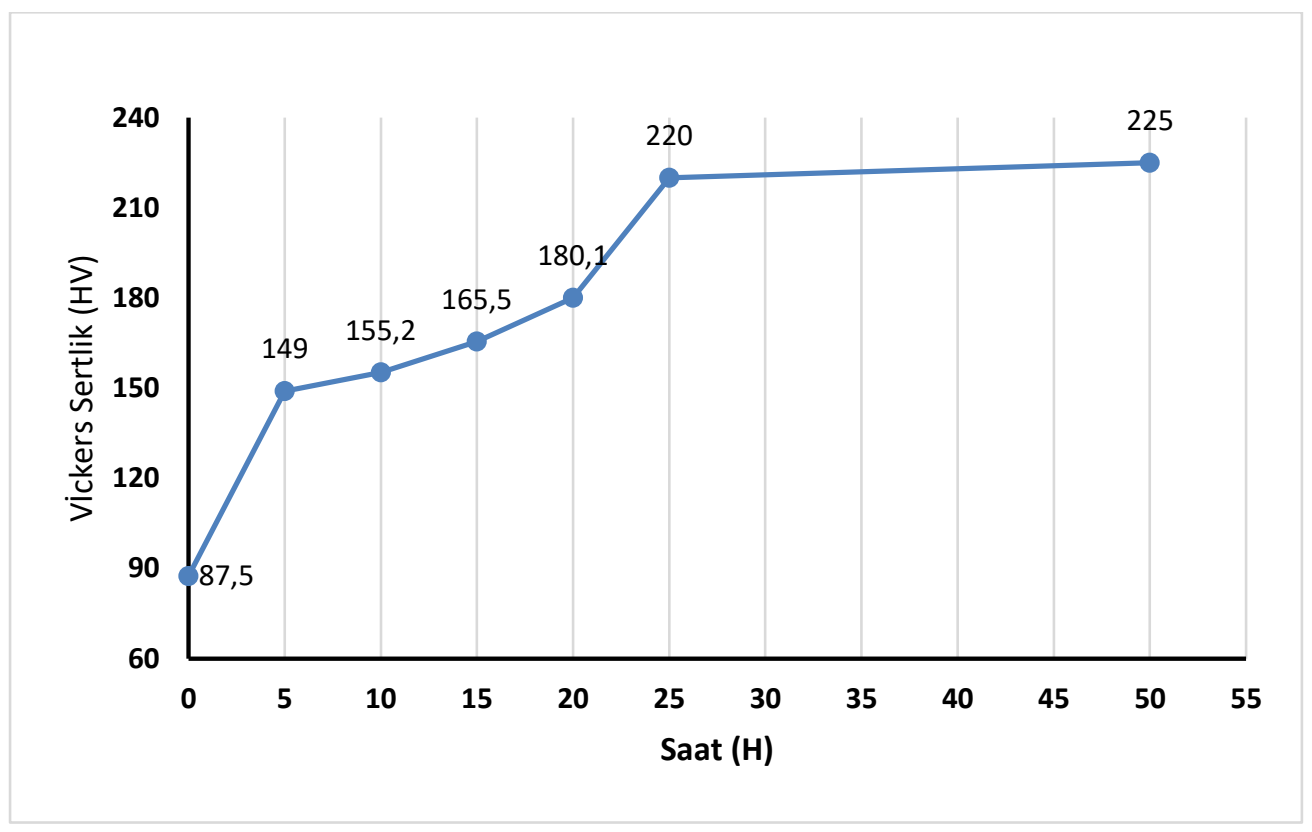

Şekil 4 Yaşlandırma ısıl işlemi sonucu AA 7075 alaşımındaki sertlik artışı

Tablo $1125^{\circ} \mathrm{C}$ de yaşlandırılmış exdrude AA 7075 alaşımının akma ve çekme mukavemeti sonuçları

\begin{tabular}{|c|c|c|c|c|c|c|c|}
\hline Legends & $\mathrm{Nr}$ & $\begin{array}{l}\mathrm{d} 0 \\
\mathrm{~mm}\end{array}$ & $\begin{array}{l}\text { EMod } \\
\mathrm{kN} / \mathrm{mm}^{2}\end{array}$ & $\begin{array}{c}\text { Fm } \\
\mathrm{N}\end{array}$ & $\begin{array}{l}\text { Rp } 0,2 \\
\mathrm{~N} / \mathrm{mm}^{2}\end{array}$ & $\begin{array}{c}\mathrm{Rm} \\
\mathrm{N} / \mathrm{mm}^{2}\end{array}$ & $\begin{array}{l}\mathrm{A} \\
\%\end{array}$ \\
\hline & 1 & 8,02 & 73,19 & 30217 & 444,39 & 598,16 & 14,19 \\
\hline & 2 & 7,98 & 65,45 & 30141 & 450,62 & 602,64 & 14,14 \\
\hline & 3 & 8 & 67,59 & 16612 & 222,08 & 330,48 & 4,20 \\
\hline & 4 & 8,02 & 72,80 & 17953 & 216,83 & 355,38 & 12,92 \\
\hline & 5 & 8,02 & 71,88 & 28858 & 430,90 & 571,25 & 13,43 \\
\hline & 6 & 8,03 & 75,10 & 15868 & - & 313,32 & 0,01 \\
\hline & 7 & 8,01 & 77,83 & 28068 & 445,00 & 556,99 & 13,76 \\
\hline & 8 & 8,02 & 76,83 & 29288 & 476,13 & 579,77 & 8,67 \\
\hline & 9 & 8,04 & 68,31 & 29555 & 502,14 & 582,15 & 11,32 \\
\hline & 10 & 8,01 & 73,53 & 29285 & 495,99 & 581,15 & 11,83 \\
\hline & 11 & 8,02 & 68,56 & 29134 & 509,79 & 576,71 & 10,63 \\
\hline & 12 & 8,01 & 81,46 & 29120 & 508,21 & 577,88 & 11,77 \\
\hline & 13 & 8,03 & 65,87 & 30362 & 538,03 & 599,52 & 11,21 \\
\hline & 14 & 8,03 & 69,38 & 27184 & 536,06 & 536,77 & 0,23 \\
\hline & 15 & 8,02 & 78,84 & 30068 & 540,07 & 595,21 & 13,04 \\
\hline & 16 & 8,03 & 72,70 & 30624 & 555,06 & 604,70 & 10,05 \\
\hline
\end{tabular}


Şekil 5 de görülen grafiklerde numunelerin çekme grafiklerinden akma davranışları çok iyi görülmektedir. Elastik bölgenin lineer olarak tamamlanmasıyla akma bölgesi başlamakta tüm numenler mükemmel bir yay çizerek kopma noktasına ulaşmaktadır. Yaşlandırma süresinin artırılması $\mathrm{MgZn}_{2}$ çökeleklerin oranını ve büyüklüklerini artırmış, akma mukavemetini yükseltmiş ancak akma davranışını değişmesine sebep olmamıştır. Yaşlandırma süresi 50 saate çıkarılsa bile çökeltilerin kristal yapıyla bağdaşıklığı bozulmamış ve aşırı yaşlanma gerçekleşmiştir.

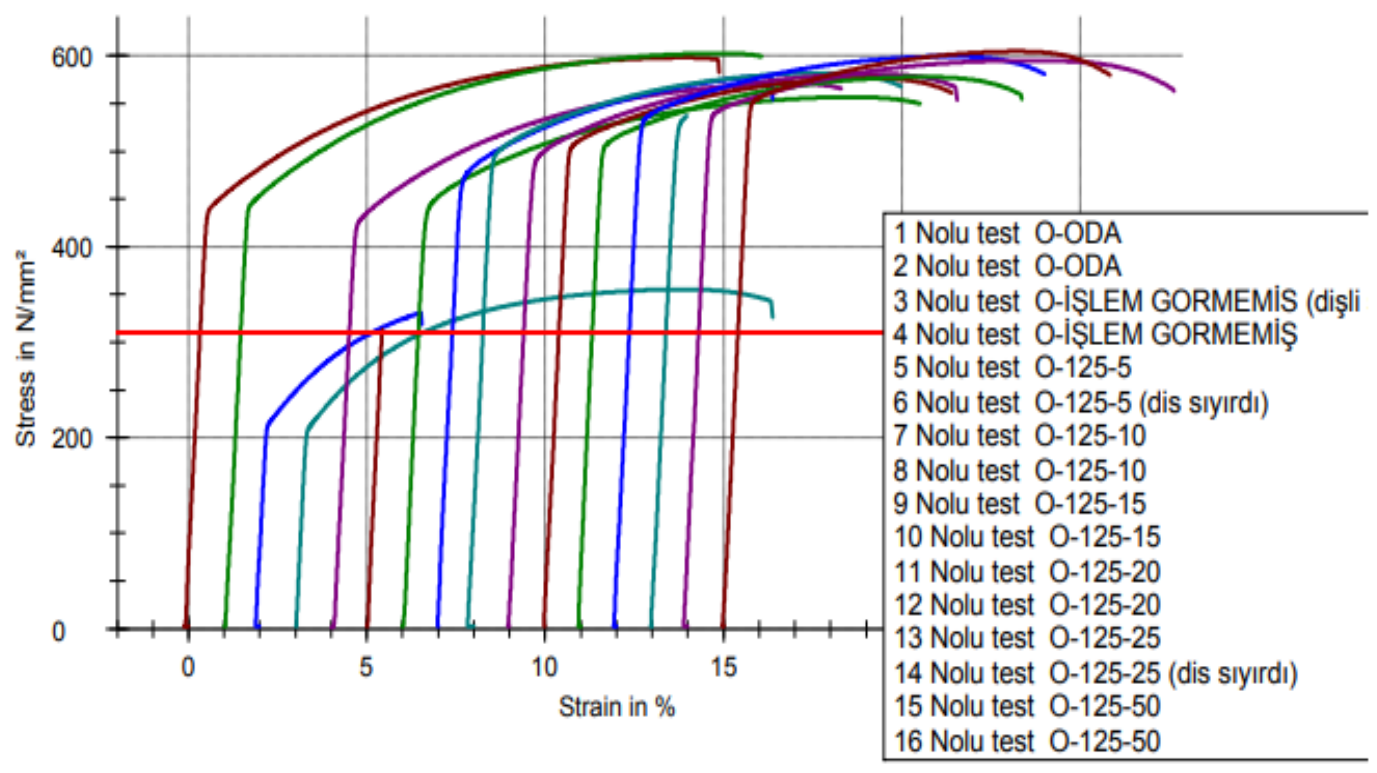

Şekil $5125^{\circ} \mathrm{C}$ yaşlandıran AA 7075 alaşımınınım çekme davranışları

AA 7075 ekstüzyon alaşımlarının çözeltiye alma şartları aynı kalmak şartıyla yaşlandırma sıcaklığı $138{ }^{\circ} \mathrm{C}$ seçilmiş ve yine farklı sürelerde yapay yaşlandırılmıştır. Yaşlandırma süreleri de yine 5,10,15,20,25 ve $50 \mathrm{~h}$ alınmış ve 1 șıl işlem deneyleri yapılmıştır. Sertleşen numuneler DIN 50125'e göre dişli kavramalı çekme numunesi standart olarak işlenmiş ve çekme testine tabi tutulmuştur. Tablo 2 de elde edilen çekme ve akma mukavemet sonuçları verilmiştir. Her ısıl işlem süresinde en az iki adet çekme testi yapılmıştır. Her test sonucu ayarı ayrı verilmiştir. Burada ortalaması alınarak tartışılacaktır. $138^{\circ} \mathrm{C}$ isıl işlem gören malzemelerden oda sıcaklığında doğal yaşlanan numune bulunmamaktadır. İki adet $5 \mathrm{~h}$ 1sıl işlem gören numunenin çekme testi yapılmış ve ortalama 517,75 MPa akma değeri ve 576,75 MPa çekme değeri bulunmuştur 10 saatlik 1sıll işlem sonucunda bu değerler sirasiyla 539,48 MPa ve 594,70 MPa, 15 saatte 522,64 MPa 578,52 MPa, 20 saatte 534,61 MPa 584,26 MPa, 25 saatte 525,26 MPa 575,98 MPa, 50 saatte 516,15 MPa $571,42 \mathrm{MPa}$ akma ve çekme mukavemet değerleri bulunmuştur. Çözelti sıcaklı̆̆ $470^{\circ} \mathrm{C}$ ve süresi 5 saat sabit tutulup yaşlandırma sıcaklığı $125^{\circ} \mathrm{C}$ den $138^{\circ} \mathrm{C}$ ye çıkarılınca yaşlandırma sonucu bağdaşı çökeleklerin oluşması kısa sürmüş ve 10 saatlik bir yaşlanma sonucunda maksimuma ulaşmıştır. $125^{\circ} \mathrm{C}$ akma değerinde süre artışına bağlı belirgin bir artış görülürken $138^{\circ} \mathrm{C}$ ' de sadece 5 saatlik ısıl işlem yeterli çökelek oluşumunu sağlamış ve $517.75 \mathrm{MPa}$ değer elde edilmiş, ancak 10 saatlik 1 sıl işlem sonucunda 539,48 MPa değeri ile maksimum akma değerine ulaşmış ve bu noktadan sonra 50 saatlik 1sıl işlem noktasına kadar azar azar bir düşüş göstermiş ve 516,16 $\mathrm{MPa}$ 
olmuştur. Çekme test sonuçları Akma sonuçlarına benzer davranış göstermiş 10 saatlik yaşlandırma 1sıl işlemi sonucunda 594,70 maksimum değerine ulaşmıştır. Bu değer $125^{\circ}$ de 50 saat yaşlandırılan değere yakındır.

Tablo $2138^{\circ} \mathrm{C}$ farklı sürelerde yaşlandırılmış numunelerin akma ve çekme mukavemet sonuçları

\begin{tabular}{c|c|c|c|c|c|c|c} 
Legends & $\mathrm{Nr}$ & $\begin{array}{c}\mathrm{d} 0 \\
\mathrm{~mm}\end{array}$ & $\begin{array}{c}\mathrm{EMod} \\
\mathrm{kN} / \mathrm{mm}^{2}\end{array}$ & $\begin{array}{c}\mathrm{Fm} \\
\mathrm{N}\end{array}$ & $\begin{array}{c}\mathrm{Rp} \mathrm{0,2} \\
\mathrm{N} / \mathrm{mm}^{2}\end{array}$ & $\begin{array}{c}\mathrm{Rm} \\
\mathrm{N} / \mathrm{mm}^{2}\end{array}$ & $\begin{array}{c}\mathrm{A} \\
\%\end{array}$ \\
\hline & 1 & 7,92 & 71,41 & 28121 & 510,09 & 570,82 & 10,13 \\
\hline \hline & 2 & 7,84 & 48,49 & 28128 & 525,40 & 582,67 & 7,71 \\
\hline \hline & 3 & 7,84 & 80,06 & 29119 & 546,70 & 603,19 & 10,35 \\
\hline \hline & 4 & 7,74 & 75,64 & 27583 & 532,26 & 586,22 & 10,31 \\
\hline \hline & 5 & 7,75 & 70,69 & 27518 & 530,33 & 583,34 & 11,94 \\
\hline \hline & 6 & 7,94 & 69,37 & 28406 & 514,94 & 573,69 & 11,43 \\
\hline \hline & 7 & 7,89 & 56,00 & 28505 & 535,46 & 583,01 & 11,63 \\
\hline & 8 & 7,89 & 64,50 & 28284 & 528,94 & 578,49 & 11,42 \\
\hline \hline & 9 & 7,9 & 73,34 & 28982 & 539,42 & 591,28 & 11,82 \\
\hline \hline & 10 & 8 & 64,01 & 28543 & 516,74 & 567,84 & 12,06 \\
\hline \hline & 11 & 7,87 & 74,28 & 28294 & 529,94 & 581,64 & 11,40 \\
\hline \hline & 12 & 7,89 & 69,33 & 28282 & 529,11 & 578,45 & 11,11 \\
\hline & 13 & 7,95 & 77,23 & 28062 & 508,06 & 565,33 & 12,72 \\
\hline & 14 & 7,92 & 71,40 & 28451 & 524,25 & 577,51 & 10,99
\end{tabular}

Şekil 6' da yaşlandırma 1sıl işlemi sonucu çökelme sertleşmesi oluşan AA 7075 numunelerin çekme eğrileri sıralı olarak tek grafikte verilmiştir. Genel olarak bakıldığında 5 saatten 50 saate kadar olan yaşlandırma sonucunda standart değerde hatta biraz üzerinde bir mukavemet artışı sağlandiğ 1 görülmektedir. Tüm çekme uzama eğrilerinin akma noktaları ve kopma noktaları açıkça görülmektedir. Akma noktasına kadar tüm numuneler lineer mukavemet artışı ile elastik davranış göstermişler, akmanın başlamasıyla da çok düzgün plastik deformasyon gerçekleşmiştir. Grafiklere mukayeseli bakıldığında akma ve çekme noktalarının birbirine yakın olduğu 10 saat yaşlandırılmış numenin akma ve çekme mukavemetlerinin en yüksek olduğu ve bu noktadan sonra yaşlanma süresinin artışına bağlı akma ve çekme mukavemetinde çok az düşüşler gözlenmiştir.

AA 7075 exrude alüminyum alaşımına $138^{\circ} \mathrm{C}$ uygulanan yaşlandırma ısıl işlemi sonucu numuneler akma ve çekme mukavemetinde oldukça yüksek artış göstermiştir. Çözeltiye almadan önceki akma mukavemeti ortalama $220 \mathrm{MPa}$ olduğu düşünülürse, yaşlandırma sonucu en yüksek elde edilen akma mukavemeti $555 \mathrm{MPa}$ dır. Bu çalışma soncunda akma mukavemeti 555/220=2,52 kat ve çekme mukavemeti 604/342=1,77 kat artırılmıştır. Buradan anlaşılacağı üzere çökelme sertleşmesi 7075 alaşımının akama mukavemetini artırmada daha etkili olmaktadır. Bunun nedeni $\mathrm{MgZn}_{2}$ çökelekleri dislokasyon hareketini engelleyerek plastik deformasyonu geciktirmiş ve akmanın daha yüksek gerilme altında meydana gelmesini sağlamıştır. Dolaysıyla işlem görmemiş numunedeki $110 \mathrm{MPa}$ olan akma ve çekme mukavemeti arasındaki fark azalmış 1 șıl işlem sonucu $60 \mathrm{MPa}$ 'a düşmüştür. $\mathrm{Bu}$ sonuçlardan ayrıca, yaşlandırma ısıl işlem ile alaşımın aşırı sünek yapısının değiştiği ve daha rigit malzeme elde edildiği söylenebilir. 


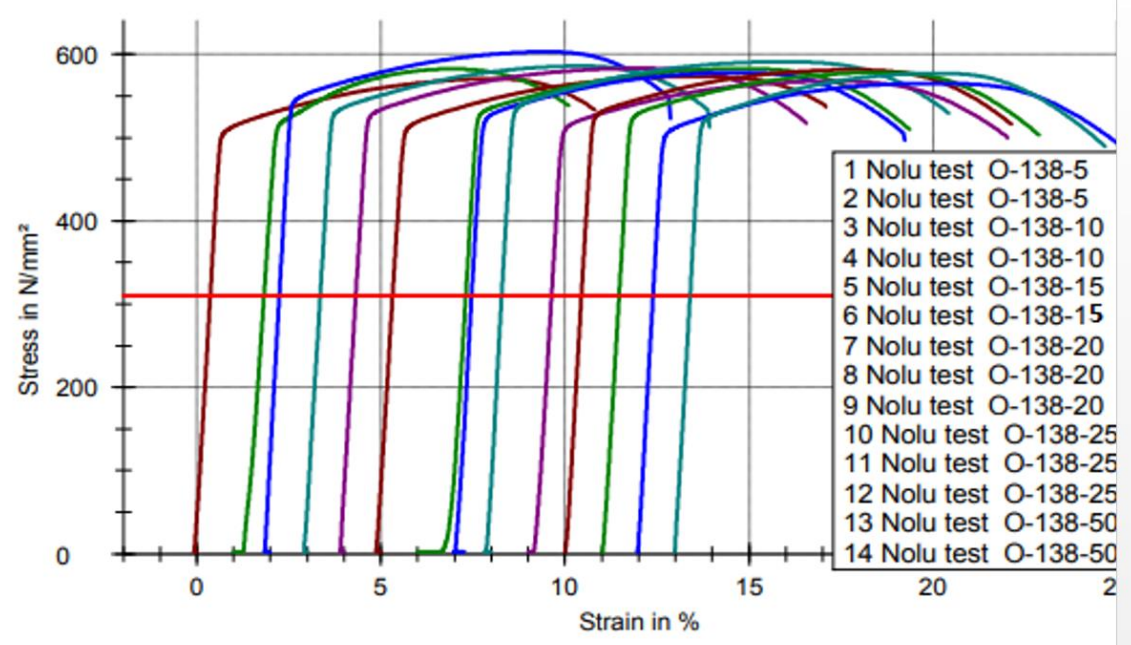

Şekil $6135^{\circ} \mathrm{C}$ yaşlandıran AA 7075 alaşımınınım çekme davranışları

125 C'de ve 138 C'de yaşlanma arasındaki farklara geldiğimizde ise 125 C'de yaşlanmada 50 saat gibi bir sürede en yüksek dayanıma ulaşırken, $138 \mathrm{C}$ 'de ise 10 saatlik yaşlandırma süresinde en yüksek dayanıma ulaşılıyor. Arada 40 saat gibi uzun bir süre farkı var, bu yüzden, 138 C'de yaşlandırma süresini ve 10 saat tercih edilmelidir.

\section{Genel Sonuçlar}

AA 7075 alaşımlarının T6 yaşlandırma 1sıl işlemi ile çökeleme sertleşmesi başarılmıştır. Yaşlandırma 1sıl işlemi sonucu bağdaşık MgZn2 çökelekleri oluşmuş 225 HV kadar sertlik artış1 sağlamıştır. Yaşlandırma 1sıl işlemi sonucu akma mukavemetinde yaklaşık 2,5 kat çekme mukavemetinde 1,8 kat mukavemet artışı gerçekleşmiş̧ir. Yaşlandırma isıl işlemi ayrıca tane sınırı fazını tane içine alarak segregasyonu minimize etmiş ve mikro yapıyı daha homojen hale getirmiştir. Havacılık sektöründe yüksek statik ve dinamik yüklere karşı güvenilir olan hafif alaşım özellikleri kazanılmıştır.

\section{Kaynaklar}

[1] S.K. Panigrahi, R. Jayaganthan, "Development of ultrafine grained high strength age hardenable Al 7075 alloy by cryorolling" Mater. Des., 32 (2011), pp. 3150-3160

[2] J. Park, "Influence of retrogression and reaging treatments on the strength and stress corrosion resistance of aluminium alloy 7075-T6" Mater. Sci. Eng. A, 103 (1988), pp. 223-231

[3] J.-F. Li, Z.-W. Peng, C.-X. Li, Z.-Q. Jia, W.-J. Chen, Z.-Q. Zheng, "Mechanical properties, corrosion behaviors and microstructures of 7075 aluminium alloy with various aging treatments", Trans. Nonferrous Metals Soc. China, 18 (2008), pp. 755-762 
[4] P. Unwin, G. Lorimer, R. Nicholson, "The origin of the grain boundary precipitate free zone", Acta Metall., 17 (1969), pp. 1363-1377

[5] K. Ma, H. Wen, T. Hu, T.D. Topping, D. Isheim, D.N. Seidman, et al., "Mechanical behavior and strengthening mechanisms in ultrafine grain precipitation-strengthened aluminum alloy", Acta Mater., 62 (2014), pp. 141-155

[6] X. Xu, J. Zheng, Z. Li, R. Luo, B. Chen "Precipitation in an Al- $\mathrm{Zn}-\mathrm{Mg}-\mathrm{Cu}$ alloy during isothermal aging: atomic-scale HAADF-STEM investigation”, Mater. Sci. Eng. A., 691 (2017), pp. $60-70$

[7] S. Kai, J.-L. Chen, Z.-M. Yin "TEM study on microstructures and properties of 7050 aluminum alloy during thermal exposure",Trans. Nonferrous Metals Soc. China, 19 (2009), pp. 1405-1409

[8] E. Lee, T. Oppenheim, K. Robinson, B. Aridkahari, N. Neylan, D. Gebreyesus, et al., "The effect of thermal exposure on the electrical conductivity and static mechanical behavior of several age hardenable aluminum alloys" Eng. Fail. Anal., 14 (2007), pp. 1538-1549

[9] B. Chen, M.F. Guo, J.X. Zheng, K.Y. Zhang, Y. Fan, L.Y. Zhou, et al., "The effect of thermal exposure on the microstructures and mechanical properties of $2198 \mathrm{Al}-\mathrm{Li}$ alloy", Adv. Eng. Mater., 18 (2016), pp. 1225-1233

[10] R. Ayer, J. Koo, J. Steeds, B. Park, "Microanalytical study of the heterogeneous phases in commercial Al-Zn-Mg-Cu alloys", Matall. Trans. A, 16 (1985), pp. 1925-1936

[11]. Rendigs K H. "Aluminium Structures Used in Aerospace-Status and Prospects", J. Mater. Sci. Forum, 242 (1997) pp. 11-24,

[12]. M. DEMIR, "Castability of Wrought 7075 Aluminum Alloys and Improvement in Mechanical Properties With T6 Age Hardening", Master Thesis, Sakarya University of Applied Sciences, Postgraduate Education Institute, 2020 